\title{
Estudo da queda livre em aulas de Física do Ensino Médio a partir de um marcador de tempo e da História da Ciência ${ }^{+*}$
}

Marco Aurélio Alvarenga Monteiro ${ }^{1}$

Universidade Estadual Paulista "Julio de Mesquita Filho"

Samuel José de Carvalho ${ }^{1}$

Estudante do Curso de Física - Universidade Estadual Paulista

Isabel Cristina de Castro Monteiro ${ }^{1}$

José Lourenço Cindra ${ }^{1}$

Universidade Estadual Paulista "Julio de Mesquita Filho"

Guaratinguetá - SP

\section{Resumo}

Já foi bastante estudado e até já se formou consenso entre os pesquisadores em Ensino de Ciências, que as atividades experimentais são muito importantes para o processo de ensino e de aprendizagem de conceitos científicos, entretanto, também são conhecidas às múltiplas e variadas dificuldades enfrentadas pelos professores em desenvolvê-las em situação real de sala de aula com seus alunos. As pesquisas também mostraram ser significativas as contribuições que a História da Ciência pode trazer para o trabalho do professor de ciências em planejar e dirigir atividades didáticas em sala de aula. Neste trabalho, propomos uma versão de um marcador de tempo de baixo-custo e de fácil construção para a determinação da aceleração da gravidade local e o uso da História da Ciência como recurso importante ao professor para o planejamento de discussões com os alunos sobre o movimento de queda livre.

Palavras-chave: Ensino de Física; Experimentação; História da Ciência; Queda-Livre.

\footnotetext{
${ }^{+}$Study of free fall in Physics lessons in the Hight School from a time marker and Science History

* Recebido: novembro de 2017.

Aceito: novembro de 2018.

${ }^{1}$ E-mails: marco.aurelio@feg.unesp.br; samueljosecarvalho@hotmail.com; monteiro@feg.unesp.br; jlcindra@uol.com.br
} 


\begin{abstract}
It has already been studied and there is already a consensus among researchers in Science Teaching, that experimental activities are very important for the teaching and learning process of scientific concepts, however, are also known to the multiple and varied difficulties faced by teachers in developing them in real classroom situation with their students. Research has also shown to be significant the contributions that the History of Science can bring to the work of the science teacher in planning and directing didactic activities in the classroom. In this work, we propose a version of a low cost and easy construction time marker for the determination of the local gravity acceleration and the use of the History of Science as an important resource to the teacher for the planning of discussions with the students on the movement of free fall.
\end{abstract}

Keywords: Physics Teaching; Experimentation; History of Science; Free Fall.

\title{
I. Introdução
}

Ao longo dos últimos sessenta anos, as pesquisas em Ensino de Ciências constataram a importância da realização das atividades experimentais para o processo de ensino e de aprendizagem de conceitos científicos. Muitos desses trabalhos já apontaram, também, as enormes e múltiplas dificuldades que os professores encontram para implementarem essa prática pedagógica em aulas da Educação Básica (GONZALES et al., 2015; OLIVEIRA, 2010; KRASILCHIK, 2005; CAPECCHI; CARVALHO; SILVA, 2002). Também por isso, o ensino de Física praticado na maioria das escolas brasileiras costuma ser descrito como desinteressante, sem contexto e baseado na passividade excessiva do aluno.

Um exemplo disso é descrito por Araújo e Abib (2003) quando afirmam que, de forma geral, o estudo da cinemática é realizado de maneira muito superficial no Ensino Médio, deixando de lado discussões interessantes do ponto de vista conceitual sobre referencial, velocidade média, velocidade instantânea e aceleração.

Considerado por muito pesquisadores como tema importante para o estudo da Física, tendo em vista sua importância histórica e epistemológica, o estudo da queda-livre é realizado tanto no Ensino Médio quanto em nível Superior (CORDOVA; TORT, 2016; COVERLONI et al., 2009).

Os experimentos clássicos de queda-livre, porém, apesar de permitirem a determinação da gravidade local com certo rigor experimental, não permitem uma boa visualização de como a posição varia com o tempo, e, portanto, de como a aceleração constante afeta o movimento de um corpo. 
Para minimizar os efeitos dessa limitação, um recurso frequentemente utilizado por livros e materiais didáticos são as imagens obtidas através das chamadas câmeras estroboscópicas.

No trabalho de Paixão (2011), o autor propõe a sobreposição de imagens obtidas em intervalos de tempo iguais, por intermédio de câmeras comuns.

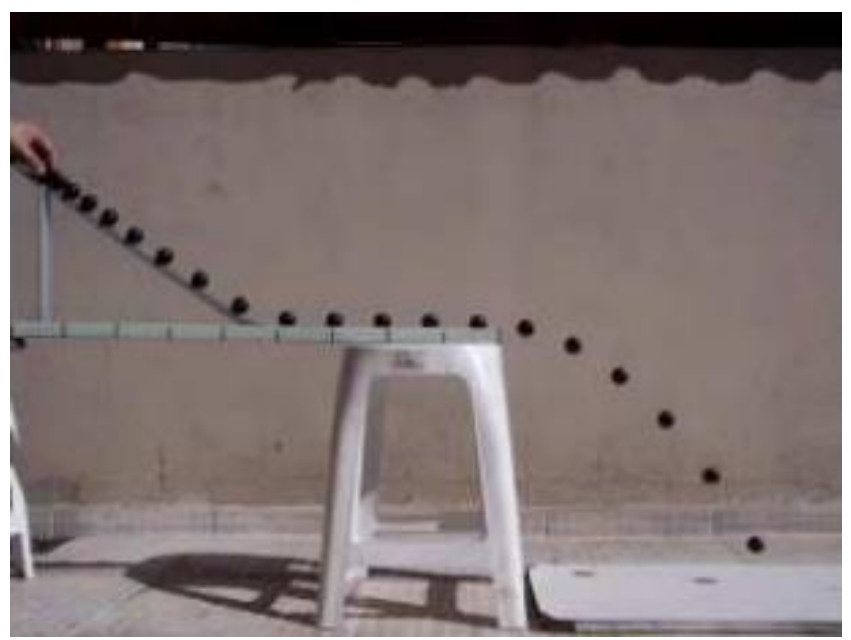

Fig. 1 - Exemplo de imagem estroboscópica. Fonte: Paixão (2011).

Entretanto, a construção dessas imagens em sala de aula exige a utilização de salas de informática com a disponibilização de computadores e softwares específicos de tratamento de imagem.

Os trabalhos de Monteiro, Santos e Teixeira (2007), Capecchi, Carvalho e Silva (2002) e Praia et al. (2002), evidenciam que somente o trabalho experimental de coleta de dados em si não é suficiente para contribuir com a aprendizagem dos estudantes. É preciso que, no contexto da experimentação os estudantes sejam envolvidos num processo de interação social a partir do qual possa ter a oportunidade de conhecer e questionar suas concepções espontâneas sobre o fenômeno estudado, levantar e testar hipóteses, construir explicações que justifiquem os resultados obtidos, bem como construir argumentos que convençam seus pares de suas opiniões.

Nesse sentido, os autores defendem a necessidade de se oportunizar aos estudantes momentos de reflexão sobre os conceitos estudados. Todavia as condições necessárias para que tal processo reflexivo se estabeleça, desencadeando as interações sociais necessárias para a troca de ideias precisam ser criadas pelo professor durante sua tarefa de conduzir a atividade didática em sala de aula.

Neste trabalho propomos a construção simples e de baixo custo de um marcador de tempo que pode propiciar aos alunos, além da vivência da prática experimental, que possibilita o desenvolvimento de habilidades e competências procedimentais, também meios para co- 
nhecer e explorar suas concepções espontâneas, para propor e testar hipóteses e, e desencadear discussões conceituais interessantes sobre velocidade média, velocidade instantânea e aceleração. Propomos, também, questões desencadeadoras de discussões baseados em fatos registrados pela História da Ciência.

\section{A atividade proposta}

A atividade experimental que propomos será descrita em três etapas:

- A construção do marcador de tempo;

- A realização do experimento; e

- A discussão dos dados obtidos.

\section{II.1 Construção do marcador de tempo}

O marcador de tempo constitui-se de um circuito elétrico simples responsável por gerar um campo magnético pulsado para que, dessa forma, uma caneta ou lápis marque pontos em uma fita de papel em movimento na mesma frequência de pulsação do campo.

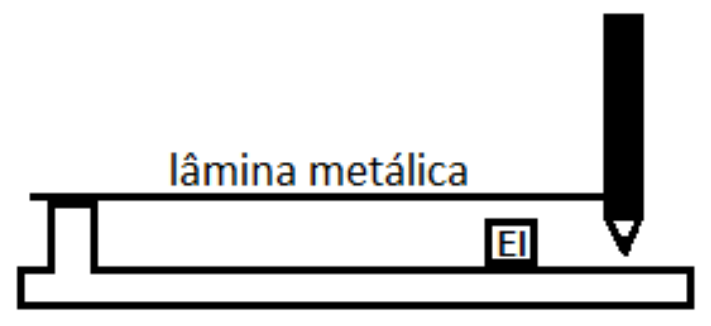

Fig. 2 - Esquema do marcador de tempo a ser construído.

Por meio da Fig. 2 mostramos o esquema do marcador de tempo que propomos que seja construído nessa atividade experimental. Ao ser acionado, o eletroímã (EI) atrai a lâmina metálica em cuja extremidade livre acopla-se um lápis ou uma caneta. Quando a lâmina toca o eletroímã a corrente cessa o lápis e caneta volta à posição anterior, para o ciclo se reiniciar.

A tensão da rede elétrica disponível em uma residência é alternada, ou seja, varia periodicamente com o tempo, no caso do Brasil, este sinal é senoidal com frequência de $60 \mathrm{~Hz}$, ou seja, 60 ciclos por segundo. Portanto, se um eletroímã for ligado diretamente a essa rede elétrica, seu campo magnético oscilará na mesma frequência, uma vez que o campo magnético induzido é diretamente proporcional à variação da corrente no tempo. Assim, o lápis ou a caneta marcará pontos num papel a cada 1/60 de segundo.

Para que o campo elétrico não seja alternado, mas pulsado, é necessário cortar os ciclos negativos do sinal senoidal, dessa forma, pode-se utilizar um diodo, ligando-o no eletroímã. O diodo é um semicondutor, muito utilizado como componente eletrônico em circuitos no quais se quer conduzir corrente elétrica somente em um sentido. 

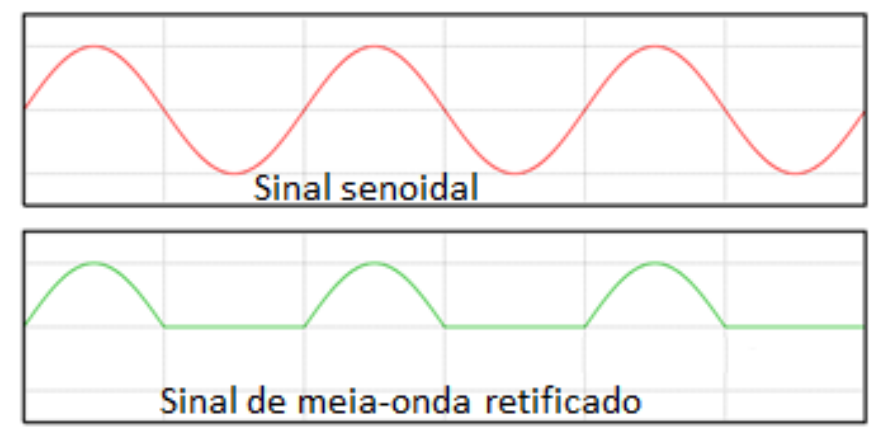

Fig. 2 - Sinal senoidal completo (acima) e sinal de meia-onda retificado por um diodo (abaixo). Fonte: Wikimedia Common (adaptado).

A seguir, apresentamos, por meio da Fig. 3, a imagem da montagem do circuito elétrico a ser montado. A montagem do circuito é bem simples e deve ser realizada utilizando fios condutores, as conexões podem ser feitas utilizando tanto a solta elétrica quanto bornes de conexão. Vale ressaltar que o diodo semicondutor encontra-se dentro do tubo azul superior, entre o eletroímã e os fios condutores.

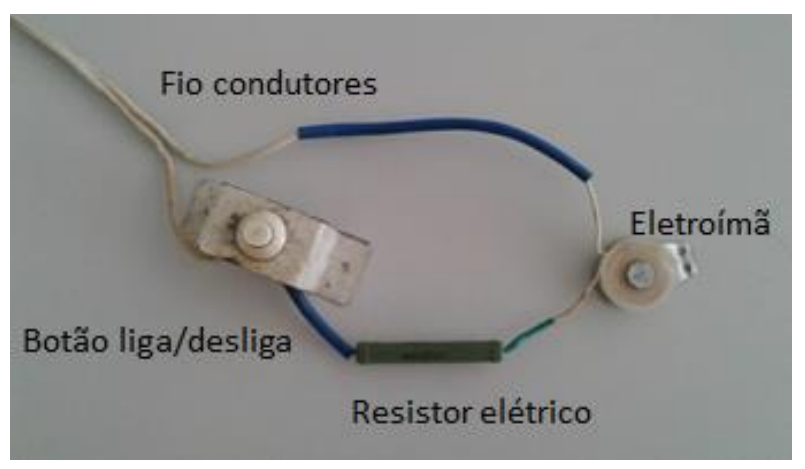

Fig. 3 - Imagem do circuito simples a ser montado.

O resistor utilizado serve para que o eletroímã não se aqueça excessivamente e queime. Para finalizar a montagem, basta ligar esse circuito em uma estrutura de madeira.

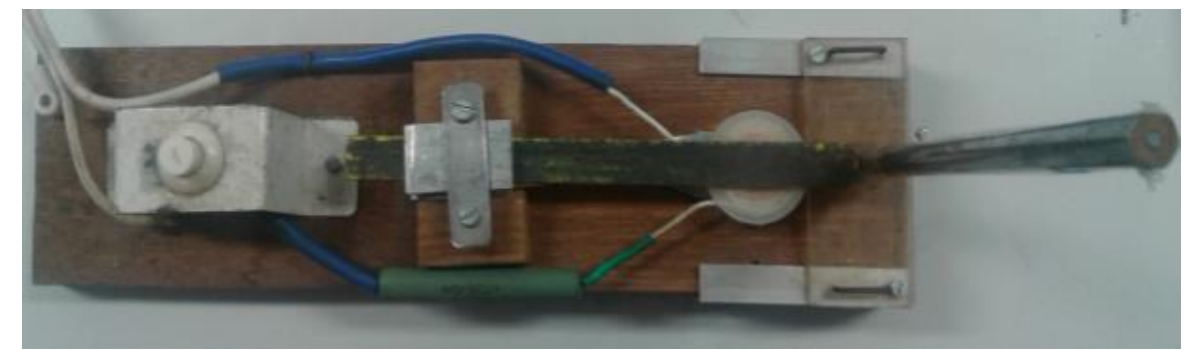

Fig. 4 - Imagem do marcador de tempo montado. 


\section{II.2 A realização do experimento}

Fazendo uma fita de papel, presa a um corpo de massa considerável, passar pelo marcador de tempo, como indica o esquema a seguir, obtém-se uma marcação de pontos com padrão análogo ao observado em uma imagem estroboscópica (Fig. 5).

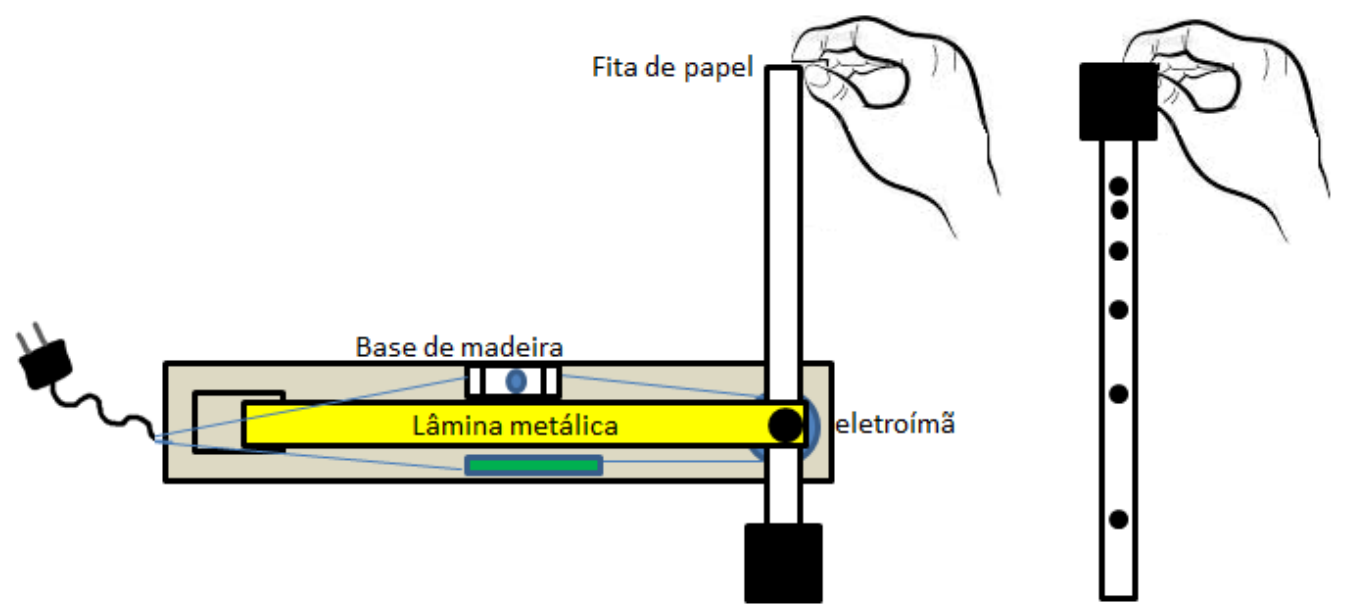

Fig. 5 - Esquema da tomada de dados.

Como a frequência em que o lápis marca os pontos na fita é igual a $60 \mathrm{~Hz}$, então é fácil concluir que o intervalo de tempo entre cada ponto marcado na fita é de $\frac{1}{60} \mathrm{~s}$, ou seja, $0,167 \mathrm{~s}$.

Em nosso experimento prendemos uma das extremidades da fita de papel a uma massa de $0,4 \mathrm{~kg}$ e os dados que obtivemos são apresentados na tabela 1 a seguir.

Tabela da posição do corpo em queda-livre em função do tempo.

\begin{tabular}{ccc}
$\begin{array}{c}\text { Posição } \\
(\mathrm{m})\end{array}$ & Tempo $(\mathrm{s})$ & $\begin{array}{c}\text { Tempo } \\
\left(\mathrm{s}^{2}\right)\end{array}$ \\
\hline 0,00000 & 0,000000 & 0,000000 \\
0,00300 & 0,016667 & 0,000278 \\
0,00625 & 0,033334 & 0,001111 \\
0,01275 & 0,050001 & 0,002500 \\
0,02225 & 0,066668 & 0,004445 \\
0,03400 & 0,083335 & 0,006945 \\
0,04900 & 0,100002 & 0,010000 \\
0,06675 & 0,116669 & 0,013612 \\
0,08725 & 0,133336 & 0,017778 \\
0,10850 & 0,150003 & 0,022501 \\
0,13580 & 0,166670 & 0,027779 \\
0,16200 & 0,183337 & 0,033612
\end{tabular}




$\begin{array}{lll}0,19530 & 0,200004 & 0,040002 \\ 0,22880 & 0,216671 & 0,046946 \\ 0,27100 & 0,233338 & 0,054447 \\ 0,31230 & 0,250005 & 0,062503 \\ 0,35300 & 0,266672 & 0,071114 \\ 0,38900 & 0,283339 & 0,080281 \\ 0,44510 & 0,300006 & 0,090004 \\ 0,48690 & 0,316673 & 0,100282\end{array}$

A partir desses dados foi possível utilizar tanto a estratégia de construir um gráfico de posição versus tempo ao quadrado em um papel milimetrado, quanto através de um software para realizar o ajuste de um polinômio de grau dois aos dados experimentais. Pode-se visualizar isso partindo da equação partindo da equação de uma queda livre:

$$
h=h_{0}+v_{0} t+\frac{1}{2} a t^{2}
$$

Considerando $\mathrm{h}_{0}$ e $\mathrm{v}_{0}$ como nulos, ou seja, o corpo sendo abandonado do repouso e posição de abandono tomada como o zero do referencial, tem-se:

$$
h=\frac{1}{2} g t^{2}
$$

De forma que a equação (II) descreve uma parábola em um gráfico de posição versus tempo, justificando a segunda estratégia apresentada, ou ainda:

$$
h=\frac{1}{2} g \tilde{t} ; \tilde{t}=t^{2}
$$

Ou seja, a equação (III) descreve uma reta em um gráfico de posição versus tempo ao quadrado, justificando a primeira estratégia. Na Fig. 6 mostramos o ajuste de uma parábola para um gráfico de posição versus tempo e uma reta para um gráfico de posição versus tempo quadrado aos dados utilizando o software Microsoft Excel.

As equações obtidas pelos dois métodos são, respetivamente, a equação (I) e a (II), o coeficiente $\mathrm{R}^{2}$, chamado coeficiente de determinação, representa o quanto os dados estão adequados à curva ajustada, quanto mais próximo este coeficiente é de 1, mais adequados ao modelo se encontram os dados obtidos. Como se pode notar, em ambos os casos o coeficiente $\mathrm{R}^{2}$ encontrado foi muito próximo de 1, concluindo um ajuste quase perfeito ao modelo.

As equações obtidas no gráfico ajustado, segundo o software, foram as seguintes:

$$
\begin{gathered}
y=4,91 x^{2}-0,0027 x+0,0004 \\
\tilde{y}=4,90 \tilde{x}^{2}-0,0003
\end{gathered}
$$




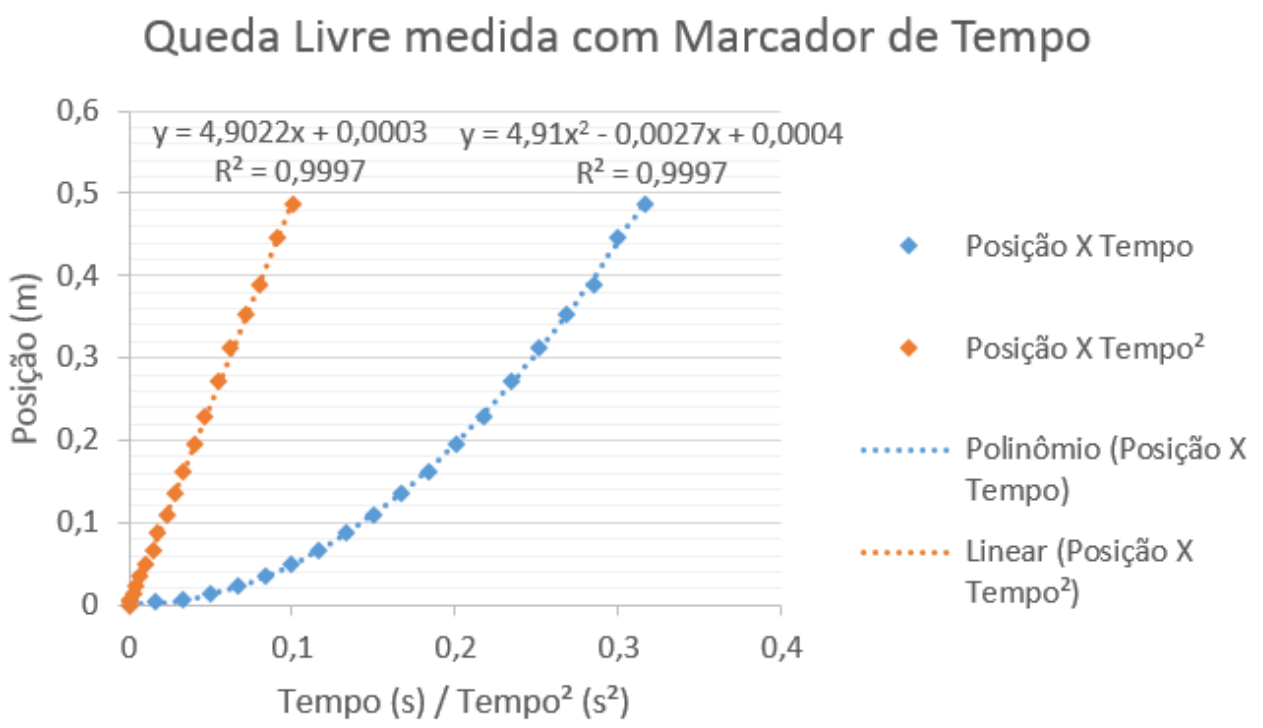

Fig. 6 - Gráfico posição versus tempo e tempo ao quadrado de um corpo em queda-livre.

Comparando estes resultados com as equações (II) e (III), obtemos a aceleração da gravidade local igual a $9,82 \mathrm{~m} / \mathrm{s}^{2}$ e $9,80 \mathrm{~m} / \mathrm{s}^{2}$ respectivamente, resultados extremamente próximos aos tipicamente adotados.

\section{II.3 Discussão dos dados obtidos}

Além de possibilitar o desenvolvimento de uma série de habilidades procedimentais como a construção do equipamento marcador de tempo, a montagem da tabela com os dados obtidos, a construção do gráfico, bem como o uso do software para os ajustes das curvas e obtenção da equação horária do movimento de queda-livre, a proposta experimental pode ser explorada visando permitir uma melhor compreensão conceitual do fenômeno.

Antes mesmo do experimento ser realizado, o professor pode provocar discussões entre os alunos no que diz respeito às "experiências de pensamento" propostas pelo físico e astrônomo italiano Galileu Galilei em seu famoso livroDiscorsi intorno a due Nuove Scien$z e$,traduzida para o português com o título "Duas Novas Ciências” (GALILEI, 1980).

Nesta sua obra Galileu propõe a seguinte experiência de pensamento: admitindo que um corpo mais pesado caísse com aceleração maior do que outro mais leve então, o que aconteceria se ao corpo mais pesado fosse preso ao corpo mais leve e ambos fossem soltos a uma determinada altura em relação ao solo? 


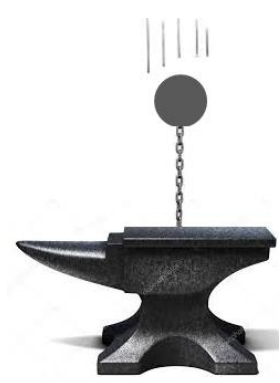

Fig. 7 - Proposição de Galileu: corpo leve ligado a um corpo pesado em queda-livre.

Ao discutir essa proposição, Galileu evidencia uma contradição óbvia: se o corpo mais leve caísse mais devagar, como se admite incialmente, então ele deveria frear o corpo mais pesado e, dessa forma, o conjunto cairia mais devagar do que o corpo mais pesado se este não estivesse ligado ao mais leve. Porém, essa conclusão destaca que, dessa forma, o conjunto, mais pesado do que o corpo mais pesado sozinho, cairia mais devagar, contrariando a premissa inicial.
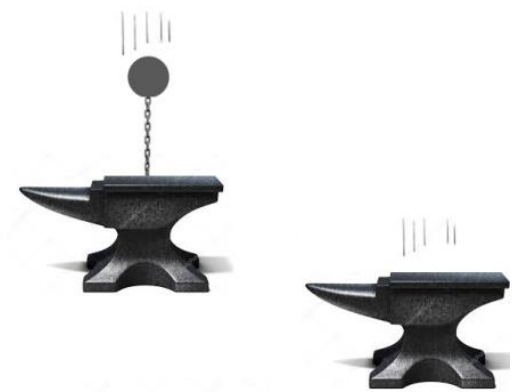

Fig. 8 - Contradição apontada por Galileu: corpo mais leve ligado a corpo mais pesado deve cair mais devagar que o corpo mais pesado sozinho?

Essa discussão inicial pode motivar os estudantes a se debruçarem sobre o tema a ser aprendido, além disso, chama atenção para um fato epistemológico interessante: uma premissa lógica nem sempre nos oferece conclusões seguras e verdadeiras, fato que motivou Galileu a completar seus estudos do ponto de vista experimental.

Galileu Galilei não dispunha de recursos precisos para medida de tempo. Há relatos em que o físico italiano fez uso de pêndulos e até mesmo da frequência de sua própria pulsação. A discussão sobre o uso da frequência de pulsação pode facilitar a ideia de se propor a construção de um marcador de tempo que se utiliza da frequência de oscilação da rede elétrica.

Historicamente sabe-se que Leonardo Da Vinci também estudou a queda dos corpos, provavelmente uma etapa de seus estudos sobre o voo, mas este estudioso, ao invés de se pre- 
ocupar diretamente com a rapidez com que um corpo cai, focou outra questão: quanto um corpo cairia em sucessivos intervalos de tempo?

Para Da Vinci um corpo em queda-livre cairia distâncias maiores para intervalos de tempos iguais. Segundo ele, para um mesmo intervalo de tempo, a sequência de aumento das distâncias seguiria a ordem dos números inteiros. Ou seja, se Da Vinci estivesse certo, os resultados da experiência proposta seria o da Fig. 9.

No primeiro intervalo de tempo o corpo cairia uma unidade de distância, no segundo intervalo de tempo, duas unidades de distância, no terceiro, três, no quarto quatro e assim sucessivamente.

Os alunos podem ser estimulados a avaliarem essa hipótese.

Galileu, mediante suas experiências de pensamento, chegou à outra conclusão: a de que as distâncias percorridas em intervalos de tempos iguais cresciam segundo a ordem crescente dos números inteiros ímpares.

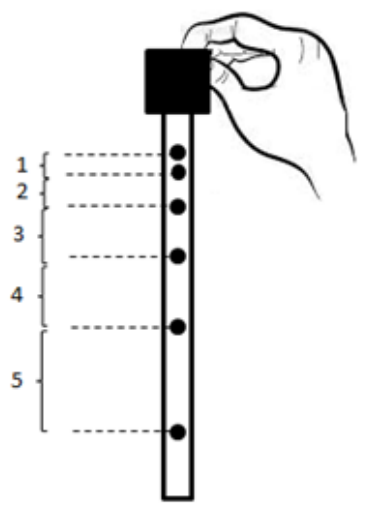

(a)

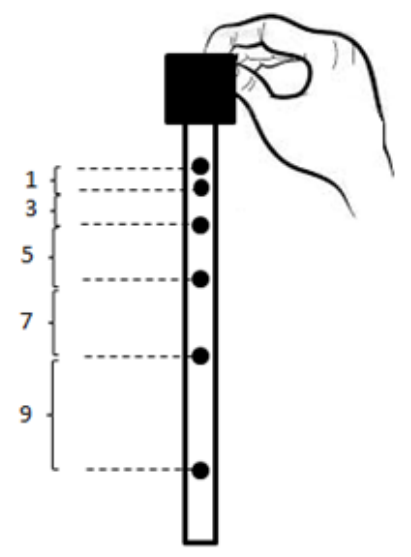

(b)

Fig. 9 (a) Proposição de Da Vinci - os corpos em queda-livre, para intervalos de tempos iguais consecutivos, caem distâncias que aumentam segundo a sequência dos números inteiros. (b) Proposição de Galileu - os corpos em queda-livre, para intervalos de tempos iguais consecutivos, caem distâncias que aumentam segundo a sequência dos números inteiros ímpares.

Os alunos podem ser convidados a verificarem essas hipóteses analisando os resultados que obtiveram.

Uma observação que pode ser feita pelo professor diz respeito à outra conclusão importante de Galileu: considerando a distância total, em um tempo qualquer ela aumentaria com o quadrado do tempo, ou seja, seria proporcional aos números naturais ao quadrado.

Nesse caso, uma discussão sobre a definição de um referencial pode ser estabelecida. 


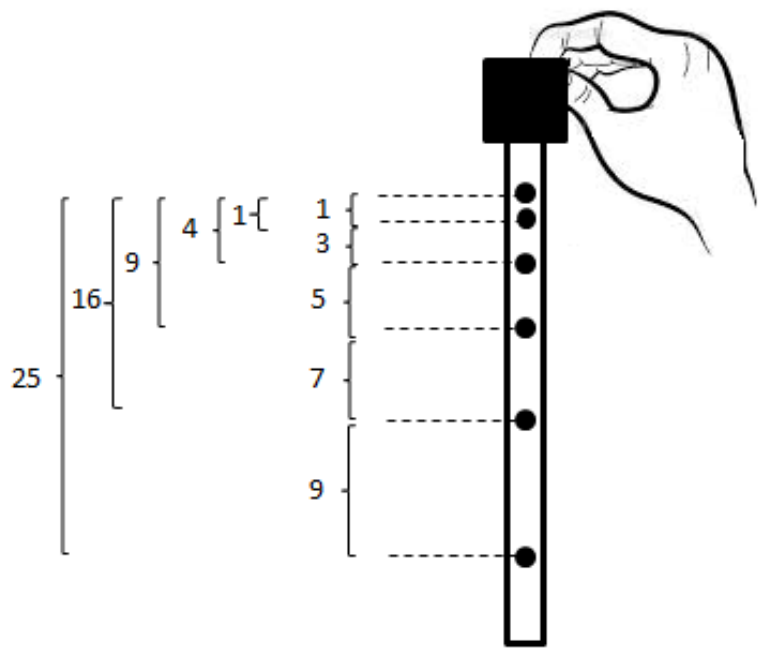

Fig. 10 - A distância de queda-livre é proporcional ao quadrado do tempo.

Isso permite levar à conclusão que a distância de queda-livre é proporcional ao quadrado do tempo.

$$
h(t) \propto t^{2} \Rightarrow h(t)=C t^{2}
$$

Retomando a questão relativa à rapidez com que o corpo cai em queda-livre, a utilização do conceito de velocidade média não reflete a realidade, já que o corpo tem velocidade igual a zero, no início da queda, e, ao chegar ao chão, tem uma velocidade maior do que a velocidade média calculada.

Neste sentido, há necessidade de se saber a velocidade instantânea, ou seja, compreender como varia a velocidade do corpo em queda livre. Contudo, antes de se analisar a variação da velocidade com o a tempo, pode-se atentar para outra hipótese: a de que a velocidade do corpo em queda-livre é proporcional à distância percorrida.

Esse tipo de hipótese não é nenhum absurdo já que o próprio Galileu chegou a acreditar nessa possibilidade.

Em seu livro Duas Novas Ciências (GALILEI, 1980), Galileu dá uma definição de movimento naturalmente acelerado.

Chamo movimento uniformemente acelerado àquele que, partindo do repouso, adquire, em tempos iguais, momentos (momenta) iguais de velocidade.

Em notação moderna podemos escrever $\mathrm{v}(\mathrm{t})=\mathrm{gt}$, onde $\mathrm{g}$ é a aceleração da gravidade local.

Ao ouvir esta afirmação de Salviati, seu interlocutor Sagredo replica que

poderíamos definir o movimento uniformemente acelerado como aquele em que a velocidade cresce em proporção ao espaço percorrido. Ao que Salviati responde: consolo-me em ter um companheiro como $V$. $S^{a}$. neste erro. 
É que Galileu, realmente, antes já havia cometido o erro de supor que a velocidade do móvel que parte do repouso cresce proporcionalmente ao espaço percorrido. Em 1604, em uma carta a seu amigo Paulo Sarpi, Galileu afirmava que havia estabelecido a lei da queda dos corpos, com base no princípio segundo o qual a velocidade crescia proporcionalmente ao espaço percorrido pelo corpo. E ainda mais ele afirmava que, com base neste princípio, pudera concluir que o espaço percorrido pelo corpo crescia na proporção do tempo ao quadrado. Mais tarde, Galileu pôde concluir corretamente que esse princípio estava errado, o correto deveria ser o princípio de proporcionalidade entre a velocidade e o tempo.

Mas como chegar na ideia de velocidade instantânea? Como chegar à expressão matemática de como essa velocidade varia com o tempo?

Nesse caso, sabemos que é preciso recorrer ao conceito de limite e de derivada, que envolve uma matemática que está além daquela tratada no Ensino Médio.

Porém, outro exercício de imaginação pode ser proposto aos alunos: vamos imaginar um corpo em queda-livre a partir de uma altura $\mathrm{H}$ em relação solo.

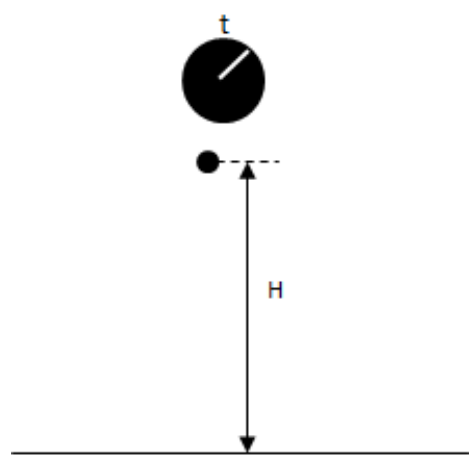

Fig.11 - Corpo a uma distância $H$ do solo inicia queda-livre no instante $t$.

Imaginemos ainda que, partindo do instante t o corpo cai uma altura durante um tempo igual a h segundos.

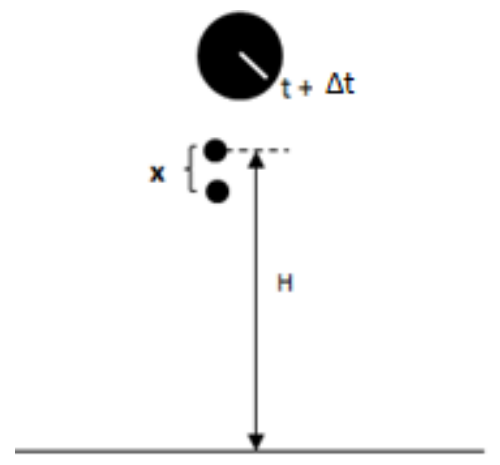

Fig. 12 - Corpo cai uma certa distância x após ter transcorrido o intervalo de tempo $t-(t+\Delta t)$ segundos. 
Calculando a velocidade média, temos:

$$
v_{m}=\frac{\Delta H}{\Delta t}=\frac{H(t+\Delta t)-H(t)}{t+\Delta t-t}
$$

Como vimos:

$$
H(t)=c t^{2}
$$

Logo,

$$
H(t+\Delta t)=c(t+\Delta t)^{2}
$$

Portanto,

$$
\begin{gathered}
v_{m}=\frac{H(t+\Delta t)-H(t)}{t+\Delta t-t} \\
=\frac{C(t+\Delta t)^{2}-C t^{2}}{\Delta t} \\
v_{m}=\frac{C\left(t^{2}+2 t \Delta t+\Delta t^{2}\right)^{2}-C t^{2}}{\Delta t} \\
v_{m}=\frac{C t^{2}+2 C t \Delta t+C \Delta^{2}-C t^{2}}{\Delta t} \\
v_{m}=\frac{2 C t \Delta t+C \Delta t^{2}}{\Delta t} \\
v_{m}=2 C t+C \Delta t
\end{gathered}
$$

Como já tínhamos concluído a velocidade média não oferece a resposta para nossa pergunta que é: com que rapidez o corpo em queda-livre varia sua velocidade?

Nossa resposta só poderá ser obtida se conhecermos a velocidade do corpo em cada instante de queda-livre. Nesse caso, o conceito que importa é o de velocidade instantânea.

Utilizando a equação de velocidade média obtida, mas imaginando que $\mathrm{h}$ é quase próximo de zero, temos uma expressão que nos permite determinar a velocidade para cada instante $t$ de queda. Ou seja, se h tender a zero, então a velocidade média é aproximadamente igual a velocidade instantânea.

$$
v_{m} \cong v(t)=2 C t
$$

Utilizando essa expressão, bem como os dados obtidos no experimento realizado, os alunos poderão determinar o valor da constante $2 \mathrm{C}$, que é conhecida como aceleração da gravidade.

$$
v(t)=g t
$$


Enfim, para concluir as discussões da atividade em sala de aula, outra observação pode ser levada aos alunos. Utilizando a expressão (VIII) temos que no instante $\mathrm{t}+\mathrm{h}$ é $\mathrm{v}=$ $2 \mathrm{Ct}+\mathrm{Ch}$, concordando com a condição que $\mathrm{vm}=[\mathrm{v}(\mathrm{t})+\mathrm{v}(\mathrm{t}+\mathrm{h})] / 2$. Portanto, a velocidade média nada mais é que a média aritmética das velocidades inicial e final, tendo em vista a linearidade de $\mathrm{v}$ em relação ao tempo.

Por outro lado, se fizermos $t=0$, temos $\mathrm{v}_{\mathrm{m}}=\mathrm{Ch}$, e consequentemente, $\Delta \mathrm{H}_{1}=\mathrm{Ch}^{2}$, que representa a distância percorrida pelo móvel no intervalo de tempo h. Agora, tomando $\mathrm{h}$ como instante inicial, podemos calcular a velocidade média no intervalo de tempo $\Delta \mathrm{t}=2 \mathrm{~h}-$ h, de modo que a velocidade média neste intervalo de tempo será

$$
v_{m 2}=3 C h
$$

E, por conseguinte, teremos $\Delta \mathrm{H}_{2}=3 \mathrm{Ch}^{2}$ e, de modo análogo, para o seguinte intervalo de tempo $\Delta \mathrm{t}=3 \mathrm{~h}-2 \mathrm{~h}$, teremos $\Delta \mathrm{H}_{3}=5 \mathrm{Ch}^{2}$, e assim sucessivamente. De modo que

$$
\begin{aligned}
& \frac{\Delta H_{1}}{\Delta H_{2}}=\frac{1}{3} \\
& \frac{\Delta H_{2}}{\Delta H_{3}}=\frac{3}{5}
\end{aligned}
$$

Galileu em "Duas Novas Ciências” (GALILEI, 1993), Terceira Jornada, Teorema II - Proposição II, escreveu:

No movimento uniformemente acelerado, quando o móvel parte do repouso, os espaços, por ele percorrido em qualquer tempo estão entre si na razão dupla do tempo, ou seja, como os quadrados desses mesmos tempos.

Portanto, temos a fórmula destacada em VI:

$$
H(t)=C t^{2}
$$

E como corolário (Corolário I) deste Teorema, Galileu escreveu:

Se tomarmos sucessivos intervalos de tempos iguais, os espaços percorridos em cada intervalo de tempo estarão entre si como os números ímpares: $1,3,5,7, \ldots$

Nessas considerações envolvendo os $\Delta \mathrm{H}_{1}, \Delta \mathrm{H}_{2}, \Delta \mathrm{H}_{3}$ servem apenas para ilustrar a validade deste corolário.

Acreditamos que essas discussões podem contribuir para o estabelecimento de interações sociais significativas para um aprendizado conceitual do fenômeno da queda-livre mais aprofundado. 


\section{Considerações finais}

As pesquisas educacionais já mostraram que a atividade experimental em sala de aula, se bem planejada e dirigida pelo professor, pode trazer oportunidades significativas de desenvolvimento dos estudantes em termos conceituais, procedimentais e até atitudinais. Os estudos em Educação para a Ciência também já demonstraram a importância da utilização da História da Ciência como fonte de recursos para a criação de contextos favoráveis a reflexão e a discussão de conceitos científicos.

A atividade que propomos para ser desenvolvida em aulas de Física do Ensino Médio visa oferecer ao professor uma alternativa de baixo custo e de fácil construção para a abordagem do estudo do fenômeno de queda-livre. Mais do que, simplesmente, propor um dinamismo diferente para as tradicionais aulas de Física baseada na fala do professor, na passividade do aluno e no excessivo tratamento lógico-matemático sem qualquer contextualização, a atividade visa envolver os estudantes num processo reflexivo onde o desencadeamento de interações sociais significativas para a aprendizagem possa se estabelecer.

Nesse aspecto, a História da Ciência, como indicam as pesquisas, se mostrou muito útil para se pensar não apenas no planejamento da atividade como na maneira de como criar contextos em que a reflexão e as discussões possam ocorrer entre os alunos, objeto de ensino e professor.

\section{Bibliografia}

ARAÚJO, M. S. T. de; ABIB. M. L. V. S. Atividades experimentais no ensino de Física: diferentes enfoques, diferentes finalidades. Revista Brasileira de Ensino de Física, v. 25, n. 2, 2003.

CAPECCHI, M. C. V. M.; CARVALHO, A. M. P.; SILVA, D. Relações entre o discurso do professor a argumentação dos alunos em uma aula de física. Ensaio - Pesquisa em Educação em Ciências, v. 2, n. 2, 2002.

CORDOVA, H.; TORT, A. C. Medida de g com a placa Arduino em um experimento simples de queda livre. Revista Brasileira de Ensino de Física, v. 38, n. 2, 2016.

CORVELONI, E. P. M.; GOMES, S.; SAMPAIO, A. R.; MENDES, A. F.; COSTA, V. L. L.; VISCOVINI, R. C. Utilização de máquina fotográfica digital (multi-burst) para aulas experimentais de cinemática-queda livre. Revista Brasileira de Ensino de Física, v. 31, n. 3, p. 3504, 2009.

GALILEI, G. Dialogues Concerning the Two New Sciences/Great. Books of the Western World 26 (Encyclopedia Britannica, Inc.,/Chicago, 1993)], publicado em 1638. 
GALILEI, G. Discorsi intorno a due nuove scienze. Opere. Torino: UTET, 1980. v. 2.

GONZALES, K. G.; GONZALES, E. G.; SABINO, J.; RIBEIRO, R. F. Reflexões sobre a função e as contribuições da experimentação no Ensino de Ciências. UNOPAR Cientifíca, Londrina, v. 16, n. 5, p. 520-527, 2015.

KRASILCHIK, M. Prática de ensino de biologia. 4 ed. São Paulo: Edusp, 2005.

MONTEIRO, M. A. A.; SANTOS, D. A.; TEIXEIRA, O. P. B. Caracterizando a autoria no discurso em sala de aula. Investigações em Ensino de Ciências, v. 12, n. 2, p. 205-225, 2007.

OLIVEIRA, J. R. S. Contribuições e abordagens das atividades experimentais no ensino de ciências: reunindo elementos para a prática docente. Acta Scientiae, Canoas, v. 12, n. 1, p. 139-153, 2010.

PAIXÃO, A. C. Conceitos básicos da cinemática utilizando a fotografia estroboscópica digital. 2011. Tese (Doutorado) - Universidade Federal do Rio de Janeiro, Rio de Janeiro.

PRAIA, J.; CACHAPUZ, A.; GIL-PÉREZ, D. A hipótese e a experiência científica em educação em ciência: contributos para uma reorientação epistemológica. Ciência e Educação, Bauru, v. 8, n. 2, p. 253-262, 2002. Disponível em: <http://vicenterisi.googlepages.com/ hipoteseeexperiencia.pdf>. Acesso em: 05 ago. 2017.

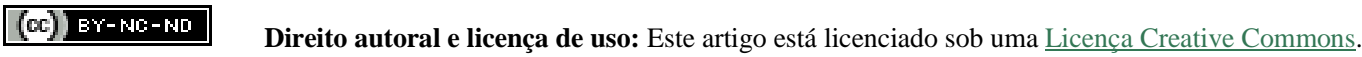

